\title{
Methane on Mars
}

\section{Yung $\mathrm{YL}^{1,2 *}$ and Chen $\mathrm{P}^{2}$}

${ }^{1}$ Division of Geological and Planetary Sciences, California Institute of Technology, CA, USA

2 Jet Propulsion Laboratory, California Institute of Technology, M/S 183-301, 4800 Oak Grove Drive, Pasadena, CA 91109, USA

\section{Finally, the Eureka Moment!}

In 2004, the first reports of methane $\left(\mathrm{CH}_{4}\right)$ in Mars' atmosphere, by both Mars Express and ground-based observations, stirred up excitement in the scientific community [1,2]. These detections (at $10 \mathrm{ppbv}$ level) immediately raised questions regarding the origin of methane. On Mars, oxidants and UV radiation destroy atmospheric methane in approximately $300 \mathrm{yrs}$ [3]. Therefore, the presence of atmospheric methane requires ongoing or recent methane emission. On Earth, methane is almost entirely of (live and fossil) biological origin, while abiotic sources, believed to be predominantly volcanic and/or hydrothermal, account for the rest (a few percent) of the total $\mathrm{CH}_{4}$ flux into the atmosphere [4]. The conventional understanding of Mars is in stark contrast: decades of exploration have not found life or active volcanism, although localized outgassing sources cannot be ruled out, and we know that past Martian volcanism until perhaps only a few million years ago had existed [5]. Consequently, a methane detection impacts Mars science and astrobiology in very fundamental ways. It turns the theoretical musing of possible life on Mars into a necessary investigation component for interpreting observational data. It elevates the possibility of hydrothermal activity on Mars, which can be habitable environments providing liquid water and redox energy to sustain life. Moreover, it compels new research directions to explore novel processes that can produce methane on Mars.

Subsequent to the 2004 reports, several teams reported high spatial and temporal variability, including plumes of up to $60 \mathrm{ppbv}$ methane. The variability posed an even greater theoretical challenge than the sheer presence of $\mathrm{CH}_{4}$. Methane's predicted 300-year atmospheric lifetime is far longer than global mixing time of about a month [69]. Hence, methane should be uniformly distributed in the Martian atmosphere. Introducing novel, much more efficient sinks can shorten the predicted lifetime [10]. However, a strong sink, whatever its nature, would also require a source that seems implausibly strong. Indeed, Lefevre and Forget [9] stated that the observed variations of methane on Mars are not explained by known atmospheric chemistry and physics at the time. However, these previous remote-sensing detection claims have been called into question, due to interference from telluric absorption in the ground-based observations, low spectral resolution in the orbital observations, and contradictions between the locations of maxima reported from ground-based observations and maps inferred by the Planetary Fourier Spectrometer (PFS) and Thermal Emission Spectrometer (TES) $[9,11,12]$.

Therefore, a definitive measurement from the Mars Science Laboratory (MSL) had been highly anticipated. In particular, MSL's Tunable Laser Spectrometer (TLS) instrument has superb spectral resolution to definitively measure methane on Mars.

Lo and behold, TLS's latest measurements indicate a background $\mathrm{CH}_{4}$ mixing ratio of $0.7 \mathrm{ppbv}$ and a pulse of 7 ppbv observed over two months [13]. These findings suggest at least two types of methane emission are at work, a constant emission producing the background level and a pulse mechanism. Some time is required for the scientific community to fully vet these results to rule out any possible sources of error [14]. If it is borne out, this discovery becomes one of the greatest
Eureka moments in the half century of robotic exploration of Mars, beginning with the first success of Mariner 4 in 1965 and reaching such ambitious milestones as the Viking landers [15-17] and Curiosity rover [18]. These intriguing findings promise to compel a new era of Mars and astrobiological research to explain methane's existence and variability in the Martian atmosphere.

\section{Potential Origins}

The question regarding the origin of methane raises tantalizing possibilities regarding potential life and habitability on Mars. As discussed above, methane's atmospheric existence requires a recent or continually replenishing source, which challenges the conventional framework of a geologically and biologically dead Mars [19].

Furthermore, methane's high variability, despite an atmospheric mixing rate that is much shorter than its chemical lifetime $[3,9,10,20,21]$, defies explanation to date. This discovery necessarily opens a new era of research pursuing answers to the questions: What is generating methane? How is it destroyed or sequestered on Mars?

Extrapolating our knowledge of terrestrial biotic sources to Mars, many consider methanogens (a type of Archaean microbe) as a probable analog to Martian life forms [22-24]. Some methanogens are able to utilize inorganic compounds $\left(\mathrm{H}_{2}\right.$ and $\left.\mathrm{CO}_{2}\right)$ as their only source of energy through the following methane-generating redox reaction $[4,22]$ :

$$
\mathrm{CO}_{2}+4 \mathrm{H}_{2}=\mathrm{CH}_{4}+2 \mathrm{H}_{2} \mathrm{O}\left(\Delta \mathrm{H}^{\circ}=-167 \mathrm{~kJ}\right) \text {. }
$$

Being independent of sunlight/photosynthesis for subsistence, methanogens thrive in deep subsurface locales where $\mathrm{CO}_{2}$ is the predominant oxidant and $\mathrm{H}_{2}(\mathrm{aq})$ is abundant from waterrock interactions (ferrous-ion reduction of $\mathrm{H}_{2} \mathrm{O}$ to $\mathrm{H}_{2}$ during serpentinization). $\mathrm{H}_{2}$ may also come from photochemical dissociation of $\mathrm{H}_{2} \mathrm{O}$ in the atmosphere [23]. In fact, methanogens thrive in some of the harshest environments on Earth, including extremely acidic environments and inside Greenland glacial ice 3-km deep, which is analogous to Martian subsurface ice environments [25-28].

Alternatively, many researchers favor Fischer-Tropsch-type (FTT) reactions as a potential methane source $[4,10,29]$. FTT is the most widely posited abiotic source of methane on Earth. Catalyzed by transition metals $(\mathrm{Ni}, \mathrm{Fe}, \mathrm{Co}, \mathrm{Cr}, \mathrm{Ru})$ and related oxides, these reactions have the same overall chemical equation as the methanogenesis reaction above,

*Corresponding author: Yung YL, Division of Geological and Planetary Sciences, California Institute of Technology, Mail Stop 150-21, Pasadena, CA 91125, USA, Tel: 626-395-6940; E-mail: yly@caltech.edu

Received January 06, 2015; Accepted January 26, 2015; Published January 31, 2015

Citation: Yung YL, Chen P (2015) Methane on Mars. Astrobiol Outreach 3: 125 doi:10.4172/2332-2519.1000125

Copyright: @ 2015 Yung YL, et al. This is an open-access article distributed under the terms of the Creative Commons Attribution License, which permits unrestricted use, distribution, and reproduction in any medium, provided the original author and source are credited. 
and take place in hydrothermal environments [30]. Abundant evidence indicates that volcanism and hydrothermal environments existed, and might still exist, on Mars [5,31,32]. If these environments do exist on current Mars, they may provide warmth and liquid water to support FTT and/or microbial methane production. Thus, $\mathrm{CH}_{4}$ in Mars' atmosphere can point to either serpentinization or the existence of life itself, both of which are associated with a hydrothermal, habitable backdrop.

Other proposed sources of Martian methane include volcanic/ magmatic degassing [33,34], exogenous delivery [35-39] and release from clathrates [40]. It would be premature to adopt or dismiss any of these hypotheses, or to suppose there can be no others.

\section{Potential Sinks}

From the surface to $60 \mathrm{~km}$ altitude, excited oxygen atoms, $\mathrm{O}\left({ }^{1} \mathrm{D}\right)$, and $\mathrm{OH}$ destroy methane. As mentioned above, the resulting methane lifetime is about 300 years, so the observed variability on timescales of months to years is unexpected. Introducing novel, much more efficient sinks can shorten the predicted lifetime [10]. It is worth noting that MSL's ChemCam instrument reported anomalous $\mathrm{O}_{2}$ depletion that appears to be temporally correlated with $\mathrm{CH}_{4}$ enhancements, evoking questions of whether an unknown oxidizing sink exists on Mars [41]. However, a strong sink, whatever its nature, would require a source that seems implausibly strong [9]. Sequestration is another possibility $[42,43]$, especially if we can find a mechanism that is both efficient enough, and reversed by changing conditions on Mars, to produce the observed methane-abundance variations.

\section{The Pulsing Sources}

While there is more than one explanation for the steady background $\mathrm{CH}_{4}$ of about $0.7 \mathrm{ppbv}$, the pulse of 7 ppbv defies a simple explanation. Because a serpentinization source would likely be located a few kilometers below the surface [30], it is difficult to concoct a release mechanism that is so confined in time. The transport from the source region to the planetary surface is a steady diffusive process and no model has produced a localized pulse. Similarly, the action of UV on organics is a diffuse process [37-39] and is not expected to prefer a particular location or time.

Analogy with the $\mathrm{CH}_{4}$ emission from terrestrial permafrost may be illuminating. Episodic bursts of $\mathrm{CH}_{4}$ from Arctic tundra have been observed during several weeks of thawing and freezing [44,45]. Each short-lived pulse of $\mathrm{CH}_{4}$ emission often equals the integral of the background emission from the rest of the year. Most of the $\mathrm{CH}_{4}$ is of microbial origin, and is produced and sequestered in the first few centimeters of soil, and then released to the atmosphere as the nearsurface thaws or freezes. Potential future investigations involving, e.g., abundance correlations with ground temperature and temporal-spatial patterns in methane abundance and stable-isotope compositions can shed light on whether or not such seasonal cryo-trapping is at work on Mars [46].

\section{Journey into the Unknown}

Resolving the methane sources and sinks on Mars will require an exploration and technology-development strategy. Existing hypotheses of Martian methane sources include gas-water-rock chemistry [30] and microbes (methanogens) [23]. If proven, the former implies the existence of environs offering liquid water and chemical sources of energy-i.e. habitability-while the latter implies the discovery of life on Mars. Solving these planetary-scale puzzles requires a concerted research effort across many disciplines. Resulting hypotheses regarding Martian methane's sources and sinks will undoubtedly call for major technological advancements, including new measurement and exploration capabilities and methodologies.

The foregoing overview points to a myriad of interrelated questions that impact future Mars exploration such as:

- Do methane-producing organisms exist in the Martian subsurface?

- Are there geological hotspots or hydrothermally-active environments generating methane on Mars?

- Are there sinks or sequestration sites for methane on Mars?

- What are the measurable signatures for hypothesized methane sources and sinks/sequestration sites?

- How does one distinguish biotic and abiotic sources using a combination of existing tools and novel methodologies?

- Can the ultraviolet degradation of accreted interplanetary or carbonaceous material explain the observed pulse of elevated methane?

Answers to these important questions dictate fundamental aspects of future Mars exploration strategy and mission design, including landing site selection, requirements for drilling capability, requirements on deployable platforms (e.g. higher mobility rovers, balloons/airships), requirements for instrument capabilities to detect relevant (e.g. molecular, isotopic, thermal, morphological) signatures, and mission durations relevant to expected dynamical time-scales. In particular, it is already clear that major advancements in instrument technology will surely be needed. Past and existing orbiting instruments have had difficulties producing convincing evidence to answer firstorder questions: Does methane exist and how much? In-situ, MSL-TLS accomplished this feat and also observed temporal variability, but it had to reach deep into its capability. The next level of questions, regarding sources, sinks, sequestration, and transport, will demand major new measurement and exploration capabilities.

A future Mars exploration program will have to bring together complementary expertise that is necessary to generate synergy in creating innovative ideas and a comprehensive roadmap. Advances in the fields of Mars exploration and instrumentation will be driven, augmented and supported by an improved understanding of deepsubsurface biogeochemistry, astrobiology, planetary geology, atmospheric chemistry, atmospheric dynamics, and remote sensing, as well as the study of Mars climate evolution, clumped-isotope analysis, stable-isotope analysis, origins of life, biosignatures, methane emissions from permafrost, and hydrothermal processes and signatures.

May the Eureka moment crystallize into a new phase of exploration with further expansion of the interdisciplinary enterprise of life and environment on Mars [47]!

\section{References}

1. Formisano V, Atreya S, Encrenaz T, Ignatiev N, Giuranna M (2004) Detection of methane in the atmosphere of Mars. Science 306: 1758-1761.

2. Krasnopolsky VA (2006) Some problems related to the origin of methane on Mars. Icarus 180: 359-367.

3. Summers ME, Lieb BJ, Chapman E, Yung YL (2002) Atmospheric biomarkers of subsurface life on Mars. Geophys Res Lett 29: 1-4.

4. Etiope G, Lollar BS (2013) Abiotic methane on Earth. Rev Geophys 51: 276299. 
5. Hauber E, Broz $P$, Jagert F, Jodlowski P, Platz T (2011) Very recent and widespread basaltic volcanism on Mars. Geophys Res Lett 38

6. Mumma MJ, Villanueva GL, Novak RE, Hewagama T, Bonev BP, et al. (2009) Strong release of methane on Mars in northern summer 2003. Science 323 1041-1045.

7. Fonti S, Marzo GA (2010) Mapping the methane on Mars. Astronomy \& Astrophysics 512.

8. Geminale A, Formisano V, Sindoni G (2011) Mapping methane in Martian atmosphere with PFS-MEX data. Planet Space Sci 59: 137-148.

9. Lefevre F, Forget $F$ (2009) Observed variations of methane on Mars unexplained by known atmospheric chemistry and physics. Nature 460: 720-723.

10. Atreya SK, Mahaffy PR, Wong AS (2007) Methane and related trace species on Mars: Origin, loss, implications for life, and habitability. Planet Space Sci 55: 358-369.

11. Zahnle K, Freedman RS, Catling D (2011) Is there methane on Mars? Icarus 212: 493-503.

12. Kerr RA (2012) Could a whiff of methane revive the exploration of Mars? Science 336: 1500-1503.

13. Webster CR, Mahaffy PR, Atreya SK, Flesch GJ, Mischna MA, et al. (2015) Mars methane detection and variability at Gale crater. Science 347: 415-417.

14. Zahnle K., (2015) Play it again SAM. Science 347: 370-371.

15. Levin GV, Straat PA (1977) Recent Results From the Viking Labeled Release Experiment on Mars. J. Geophys. Res. 82: 4663-4667.

16. Soffen GA (1977) The Viking Project. J. Geophys. Res. 82: 3959-3970.

17. Klein HP (1999) Did Viking discover life on Mars? Origins of Life and Evolution of the Biosphere 29: 625-631.

18. Grotzinger JP, et al. (2012) Mars Science Laboratory Mission and Science Investigation. Space Science Reviews 170: 5-56.

19. Allen M, Lollar BS, Runnegar B, Oehler DZ, Lyons JR, et al. (2006) Is Mars alive? EOS 87: 433-439.

20. Nair H, Summers ME, Miller CE, Yung YL (2005) Isotopic fractionation of methane in the martian atmosphere. Icarus 175: 32-35.

21. Yung YL, Russell MJ, Parkinson CD (2010) The Search for Life on Mars. J Cosmol 5: 1121-1130.

22. Boston PJ, Ivanov MV, McKay CP (1992) On the possibility of chemosynthetic ecosystems in subsurface habitats on Mars. Icarus 95: 300-308.

23. Weiss BJ, Yung YL, Nealson KH (2000) Atmospheric energy for subsurface life on Mars. P Natl Acad Sci USA 97: 1395-1399.

24. Schulze-Makuch D, Fairén AG, Davila AF (2008) The case for life on Mars. Int J. Astrobiol 7: 117-141.

25. Stevens TO, McKinley JP (1995) Lithoautotrophic microbial ecosystems in deep basalt aquifers. Science 270: 450-454

26. Chapelle FH, Neill KO, Bradley PM, Methe BA, Ciufo SA, et al. (2002) A hydrogen-based subsurface microbial community dominated by methanogens. Nature 415: 312-315

27. Walker JJ, Spear JR, Pace NR (2005) Geobiology of a microbial endolithic community in the Yellowstone geothermal environment. Nature 434: 10111014

28. Tung HC, Bramall NE, Price PB (2005) Microbial origin of excess methane in glacial ice and implications for life on Mars. P Natl Acad Sci USA 102: 18292 18296

29. Oze C, Sharma M (2005) Have olivine, will gas: Serpentinization and the abiogenic production of methane on Mars. Geophys Res Lett 32.

30. Lyons JR, Manning C, Nimmo F (2005) Formation of methane on Mars by fluidrock interaction in the crust. Geophys Res Lett 32: L13201.
31. Schulze-Makuch MD, Dohm JM, Fan C, Fairen AG, Rodriguez JAP et al. (2007) Exploration of hydrothermal targets on Mars. Icarus 189: 308-324.

32. Squyres SW, Arvidson RE, Ruff S, Gellert S, Morris RV, et al. (2008) Detection of silica-rich deposits on Mars. Science 320: 1063-1067.

33. Etiope G, Klusman RW (2002) Geologic emissions of methane to the atmosphere. Chemosphere 49: 777-789.

34. Ryan S, Dlugokencky EJ, Tans PP, Trudeau ME (2006) Mauna Loa volcano is not a methane source: Implications for Mars. Geophys. Res. Lett 33: L12301.

35. Kress ME, McKay CP (2004) Formation of methane in comet impacts: implications for Earth, Mars, and Titan. Icarus 168: 475-483.

36. Krasnopolsky VA, Maillard JP, Owen TC (2004) Detection of methane in the martian atmosphere: evidence for life? Icarus 172: 537-547.

37. Keppler F, Vigano I, McLeod A, Ott U, Früchtl M, et al.(2012) Ultravioletradiation-induced methane emissions from meteorites and the Martian atmosphere. Nature 486: 93-96.

38. Schuerger AC, Moores JE, Clausen CA, Barlow NG, Britt TD (2012) Methane from UV-irradiated carbonaceous chondrites under simulated Martian conditions. J Geophys Res 117: E08007.

39. Poch O, Kaci S, Stalport F, Szopa C, Coll P (2014) Laboratory insights into the chemical and kinetic evolution of several organic molecules under simulated Mars surface UV radiation conditions. Icarus 242: 50-63.

40. Chastain BK, Chevrier V (2007) Methane clathrate hydrates as a potentia source for martian atmospheric methane. Planetary \& Space Science 55: 12461256

41. McConnochie TH, Smith MD, Bender S, et al. (2014) ChemCam passive spectroscopy of atmospheric $\mathrm{O} 2$ and $\mathrm{H} 2 \mathrm{O}$. Eighth International Conference on Mars, Pasadena, CA, Jul. 2014

42. Gough RV, Turley JJ, Ferrell GR, Cordova KE, Wood SE, et al. (2011) Can rapid loss and high variability of Martian methane be explained by surface $\mathrm{H}_{2} \mathrm{O}_{2}$ ? Planet Space Sci 59: 238-246.

43. Jensen SJ, Skibsted J, Jakobsen SH, Ten Kate IL, Gunnlaugsson HP, et at. (2014) A sink for methane on Mars? The answer is blowing in the wind. Icarus 236: $24-27$.

44. Mastepanov M, Sigsgaard C, Dlugokencky EJ, Houweling S, Ström L, et al. (2008) Large tundra methane burst during onset of freezing. Nature 456: 62830 .

45. Song C, Xu X, Sun X, Tian, Sun L, et al. (2012) Large methane emission upon spring thaw from natural wetlands in the northern permafrost region. Environ Res Lett 7: 034009.

46. Hu R, Gao P, Miller CE, Yung YL (2015) Hypotheses for a Near-Surface Reservoir of Methane and Its Release on Mars. 46th Lunar and Planetary Science Conference. Abstract 2279

47. Rummel JD, Beaty DW, Jones MA, Bakermans C, Barlow NG, et al. (2014 A New Analysis of Mars "Special Regions": Findings of the Second MEPAG Special Regions Science Analysis Group (SR-SAG2). Astrobiology 14: 887968. 